\title{
Cultural Congruence Test for Russian Adolescents
}

\author{
Larisa F. Bayanova ${ }^{\star}$, Oleg G. Minyaev \\ Kazan Federal University, Kazan, Russia \\ ${ }^{*}$ Corresponding author. E-mail: balan7@yandex.ru
}

Background. Cultural congruence serves as a measure of the conformity of an adolescent's behavior to age-specific rules inherent in a particular cultural context. A cultural context is a system of situations with pre-set behavior-regulating rules.

Objective. Rule-based behavior management is known to be an issue in adolescence. Teenagers often defy common rules, thus pitting themselves against adults. In our study, we recruited adolescents between the ages of 12 and 15 years $(\mathrm{N}=699)$ who completed a questionnaire on the rules that they have to comply with in their day-to-day lives.

Design. Based on 2,498 responses, we identified 70 rules that were mentioned in $98.15 \%$ of the responses. We then designed a cultural congruence diagnostics test to measure the extent to which an adolescent's behavior fits invariable age-specific rules in the Russian cultural context. The rules are combined into four factors: management, safety, studies, and social interaction.

Results. These factors appear to be in line with existing theories on the adolescents' social context. According to cultural and historical psychology, peers are considered as the most important subjects that adolescents interact with within their social context; this is confirmed by relevant items in the questionnaire. Studies, the factor that dominates in the pre-adolescent age, are still relevant, which is why the test features such factors as studies and management. Safety emerges as an important factor in the cultural congruence test for preschool children and primary school students. This factor helps regulate behavior in adolescence since safety rules are part of the typical rules in the adolescent cultural context.

Conclusion. The test design features the following psychometric properties: internal consistency of the scale (Cronbach's alpha), discriminatory power (Ferguson's coefficient), validity, and reliability.

(C) Russian Psychological Society, 2019

http://psychologyinrussia.com

Keywords: adolescent, behavior, normative situation, cultural congruence. 


\section{Introduction}

Adolescence has been a major focus area in Russian psychology due to the fact that both parents and teachers face the largest number of issues dealing with 12- to 15 -year-old teenagers. In our research into teenage rule-fitting behavior, we proceeded from the assumption that there is an invariable set of rules that are specifically typical for 12- to 15-year-old adolescents. Research shows that the personal development of a teenager is aimed at finding an image of an adult, whom he or she would like to be like (Vygotsky, 1982; Feldstein, 2010; Dubrovina \& Prikhozhan, 2010; Polivanova \& Korzun, 2017; Lazareva, 2009; Lavrichenko, 2013). Russian psychologists believe that by the age of fifteen, a teenager should acquire a subjective sense of himself as an adult - a "feeling of adulthood." This complex process of a teenager identifying with an adult image produces conflicts with parents and teachers. The source of the conflict is the contradiction between the teenager's desire to be an adult, and the failure of his parents and teachers to recognize him or her as an adult.

The complexity of the formation of the teenage personality is confirmed in Lichko's works, where it is shown that about $50 \%$ of teenagers have accentuated personalities (Lichko, 2010). The teenage years are the phase of the highest suicide rate, along with some adolescents committing crimes or getting drawn into asocial subcultures. According to the World Health Organization, suicides resulted in 814,000 deaths in 2010, of which about $20 \%$ were in adolescence (Grachev \& Bazhinova, 2016).

These aspects have driven an intense interest in this age group among psychologists. Most commonly, practicing psychologists receive requests from parents and instructors to consult on the teenagers' reluctance to comply with the rules established by adults. Indeed, adolescence is the most challenging period in terms of behavior regulation, and is often called an age of crisis when teenagers tend to break rules. There is a quite high degree of delinquency among teenagers. Studies by N. Grudinina and V. Griaznova reported that in 2015, 55,365 crimes were committed by teenagers; that's 1203 offenses per 100 thousand people in Russia (Grudinin \& Gryaznov, 2015).

Are there invariable adolescence-specific rules that are supposed to regulate teenage behavior? If we had such a fixed list with the main day-to-day rules, could we possibly measure how well a teenager's behavior fits those rules?

We designed a test to measure how well a teenager's behavior fits the social environment. It relies on a questionnaire used to assess the level of cultural congruence. In our paradigm, culture is a set of situations with inherent behavior-regulating rules (Veraksa, 2000). We've produced similar tests for 5-6 year-old children (Bayanova \& Musstafin, 2016) and 7-11 year-old school students (Bayanova et al., 2016). The tests are designed to measure the level of cultural congruence, i.e., conformity to the invariable rules that are supposed to regulate a child's behavior in the environment he or she occupies.

Analysis of the literature on the adolescent vs. rule interaction demonstrates that there is active interest in this topic in contemporary developmental psychology. We looked at the latest papers that examine the issue. In her study, Ana R. Urmeneta examines the impact of social norms and rules vis-a-vis the development 
of sociological thinking in children. She presents culture as a multi-faceted system of values, norms, and role models that regulate the behavior of individuals and social groups. Her findings reveal the existence of sociological thinking in children, which means that it can be safely stated that children have an active outlook on the social world, which involves them thinking, analyzing, and creating their own hypotheses on how the social institutions and the society they belong to work. This brings Urmeneta to the conclusion that teenagers cannot continue to be viewed as passive subjects, nor can their action potential be underestimated. They have their own ways of interpreting, constructing, and actively influencing their social world. Children's sociological thinking is produced within a specific social context where school plays a prominent and influential role. (Urmeneta, 2014).

Faizah Bte Abdul Ghani, Suraya Lin bt Abdullah Kamal, and Azian bt Abd Aziz examined the implications of parenting styles on Muslim teenagers. The authors are convinced that lack of parental control leads to delinquency. Most of the respondents' parents practiced authoritative styles. Malaysian parents want their children to comply with all the family's requirements and rules. Upon correlation analysis, the researchers concluded that the authoritative parenting style has a positive relationship to the students' academic performance (Ghani, Kamal, \& Aziz, 2014).

In their study of foster youth, David Mullins and Marie S. Tisak assessed whether children and adolescents differentiate between moral, social-conventional, and personal rules. The results suggest that foster youths' judgments distinguished between the moral, conventional, and personal domains. However, in providing reasons to support their judgments or evaluations, the foster youth referred to social-conventional reasoning even when evaluating moral and personal rules and violations, while their peers who lived with their biological parents focused more on punishment in case of transgression (Mullins \& Tisak, 2006).

Olivier Desrichard, Sébastian Roché, and Laurent Bègue examined why adolescents, boys in particular, tend to violate driving rules, and how their behavior is related to parental supervision. Over the last quarter century, road accidents have remained the largest single cause of mortality among 15 to 25 year-olds in most European countries. In the majority of cases, accidents occur in situations where one or more driving rules have been violated. The effect of the role of parents shows that adolescents growing up in a family with strong parental supervision have a more negative attitude toward violating driving rules and, consequently, have less intention of doing so. The findings also show that girls are more supervised by their parents and commit fewer offenses than boys (Desrichard, Roché, \& Bègue, 2007).

Susanne Pedersen, Alice Gronhoj, and John Thøgersen studied the link between social norms and healthy eating among adolescents. The survey, completed by 757 teenagers, revealed vulnerability to peer pressure. Those who generally embraced healthy eating acknowledged that in a situation where their peers or friends consume unhealthy food, they would also violate the rule (Pedersen, Gronhoj, \& Thøgersen, 2015).

Tara D. Warner, Peggy C. Giordano, Wendy D. Manning, and Monica A. Longmore investigated the impact of social norms on sexual activity in adolescence. The authors believe that the line between what is acceptable and unacceptable in sexual 
behavior has shifted significantly. According to their study, teenagers internalize norms of social behavior based on imitating and analyzing other people's activities. This approach confirms the authors' commitment to A. Bandura's social learning theory. Peer influence is particularly strong in this respect. Even during a gang rape situation, studies indicate, adolescents commit the crime because of group conformity - the desire to match the expectations of others, and demonstrate that they are part of the group. This is why emerging sexual behavior in adolescence is studied with connection with socialization in general (Warner, Giordano, Manning, \& Longmore, 2011). American researchers (Frisco, 2008; Kaestle \& Halpern; Meier, 2007) confirmed that there is indeed a link between the number of sexual contacts in adolescence and the social status of their neighborhoods since, the authors believe, location has an impact on whether teenagers adopt certain rules and comply with norms. Teenagers who live in a socially disadvantaged neighborhood turn out to have a higher chance of an early sexual debut and a higher proven number of sexual partners.

In studying adolescence, Russian psychology relies on Lev Vygotsky's social development theory. According to Vygotsky, each age represents a specific social development situation; there is an age-specific type of social interaction between a child and the environment (Vygotsky, 1978; Vygotsky, 1982; Vygotsky, 1996; Veraksa, N., \& Veraksa, A., 2018). Behavior is regulated by social rules; therefore any research into behavior cannot ignore culture-inherent rules.

Within the diverse literature on adolescent rules, there have been no papers on invariable, typical rules that regulate a teenager's behavior in a specific cultural context. There have been no diagnostic tests that measured the level of compliance with the invariable rules inherent in a cultural context, i.e., cultural congruence. Therefore, our study pursued two goals:

1. Identifying invariable rules specific to Russian culture that regulate teenage behavior.

2. Designing a diagnostic test to measure an adolescent's cultural congruence, i.e., the extent to which his or her behavior is in line with typical rules.

\section{Methods}

\section{Sample and Participant Selection}

Our sample included 734 respondents. Thirty-five were excluded from the original sample due to incomplete data, and thus the final list featured $\mathrm{N}=699$. The adolescents were between 12 and 15 years old $(M=13.86, S D=0.91)$. Among them were 296 girls (42.34\%) and 403 boys (57.66\%). Both parental consent and participant's consent for minors were obtained for all participants. The participation rate was high (97\%).

All participants received an agreement to sign and an information sheet. The informed consent was agreed upon with the children involved, and was rediscussed during the study. Pseudonyms have replaced the names of participants. Participants were given the opportunity to leave the study at any time. The research was carried out in accordance with Code of Ethics of the Russian Psychological Society. 


\section{Procedure}

\section{Questionnaires}

Based on our research goals - identifying an invariable list of adolescence-specific rules and designing a compliance diagnostics test - we conducted an empirical study along the following timeline:

Stage 1: Adolescents complete a questionnaire providing a list of rules that they deal with on a day-to-day basis.

Stage 2: Based on the frequency analysis, we identify the most frequently mentioned rules.

Stage 3: We design a questionnaire for adolescents to measure their level of cultural congruence, i.e., their conformity to rules, and verify the reliability and validity of the diagnostics test.

In Stage 1, adolescents completed the following questionnaire:

1. Which rules are familiar to you and easy to comply with?

2. Compliance with which rules will guarantee approval and praise from adults?

3. Violation of which rules is followed with a reprimand or punishment from adult parents?

4. Violation of which rules is followed with a reprimand or punishment at school?

5. Which rules do you prefer to follow in your relationships with your peers?

6. Violation of which rules in your relationships with peers is unacceptable?

7. Which rules must you comply with after school?

8. Which rules restrict your behavior?

9. Which rules are particularly difficult for you to comply with?

10. Which rules do you prefer to follow in an unfamiliar situation?

In Stage 2, it was important to select the high-frequency rules that are typical for the majority of the respondents. Out of 2,498 responses, we identified 70 rules that were found in 98.15 percent of all the responses using the frequency analysis. Based on these 70 rules, we designed a questionnaire where adolescents were asked to evaluate each of the rules according to the following instruction: "Please rate the rules on five-point scale, where:

$1=\mathrm{I}$ never follow the rule.

$2=$ I would rather break the rule because I do not believe it is binding.

$3=\mathrm{I}$ may follow the rule, but I may also choose to break it.

$4=\mathrm{I}$ take the rule as guidance.

$5=$ I always strictly follow the rule."

\section{Results}

The outcomes of the questionnaire were exposed to factor analysis by means of varimax rotation, with four factors identified: management, safety, studies, and social interaction (see Table 1). 
Table 1

Adolescence Cultural Congruence Factors

\begin{tabular}{rll}
\hline No. & Factor 1: Studies & \\
\hline 1 & Be polite & .608 \\
2 & Behave yourself & .583 \\
3 & Get good marks & .576 \\
4 & Obey people older than you & .566 \\
5 & Behave in a decent way & .556 \\
6 & Comply with etiquette rules & .521 \\
7 & Do your homework & .520 \\
8 & Do not argue with instructors & .509 \\
9 & Respect people older than you & .497 \\
10 & Comply with dress code, dress neatly & .495 \\
11 & Help everyone / each other & .485 \\
12 & Do not be late & .484 \\
13 & Do not speak during class & .459 \\
14 & Respect others & .441
\end{tabular}

\begin{tabular}{rll}
\hline No. & Factor 2: Management & \\
\hline 1 & Exercise in the morning & .658 \\
2 & Go to bed at the right time & .614 \\
3 & Follow your daily regimen & .591 \\
4 & Do not spend too much time on social media & .580 \\
5 & Have your meals at the right time & .572 \\
6 & Eat healthy food & .544 \\
7 & Keep upright posture & .532 \\
8 & Make your bed & .516 \\
9 & Keep your room clean and tidy & .506 \\
10 & Do not play computer games & .503 \\
11 & Wash the dishes & .490 \\
12 & Do not cheat other people & .475 \\
13 & Wake up at the right time in the morning & .471 \\
14 & Plan your day in advance & .448 \\
\hline No. & Factor 3: Safety & \\
\hline 1 & Do not leave without informing your parents \\
2 & Do not stay out too late & .682 \\
3 & Do not play with matches/fire & .647 \\
4 & Do not harass the other gender & .645 \\
5 & Do not use obscenities in your conversations with friends & .591 \\
6 & Do not miss classes & .588 \\
7 & Do not engage in brawls & .517 \\
8 & Do not drink alcoholic beverages & .503 \\
9 & Do not laugh at your teacher & .502 \\
& & .501 \\
\end{tabular}


10 Do not smoke

11 Do not use foul language

12 Do not talk with strangers

13 Follow school rules

14 Take care of yourself

\section{No. Factor 4: Social Interaction}

1 Be a good friend

2 Be appreciative

3 Keep your promise

4 Do not inform on your friends

5 Be strong enough to defend yourself

6 Do not offend each other

7 Give up your seat to seniors

8 Do not take someone else's belongings without permission

9 Respect the opinions of other people
.629

.577

.566

.559

.558

.460

.448

.437

.427

These four groups of invariable rules regulating the behavior of Russian adolescents are the backbone of the cultural congruence diagnostic test. In line with the methodological design, we then made psychometric calculations of validity and reliability. Table 2 demonstrates that Cronbach's alpha value is statistically relevant. High values confirm internal consistency of the scale.

Table 2

Cronbach's alpha values

\begin{tabular}{lcc}
\hline & Cronbach's alpha & Number of items \\
\hline Management & 0.873 & 14 \\
Safety & 0.893 & 14 \\
Studies & 0.882 & 14 \\
Social interaction & 0.790 & 9 \\
Overall cultural congruence & 0.949 & 51 \\
\hline
\end{tabular}

Table 3

Ferguson's coefficient values

\begin{tabular}{lccccc}
\hline & $\boldsymbol{\Sigma} \mathbf{f i}$ & $\boldsymbol{\Sigma f f}^{\mathbf{2}}$ & $\mathbf{k}^{*}$ & & $\boldsymbol{\Delta}$ \\
\hline Management & 699 & 15,064 & 14,715 & 1.00007 & $\mathbf{0 . 9 6 9}$ \\
Security & 699 & 17,499 & 17,150 & 1.00006 & $\mathbf{0 . 9 6 4}$ \\
Studies & 699 & 18,683 & 18,334 & 1.00005 & $\mathbf{0 . 9 6 2}$ \\
Social interaction & 699 & 41,839 & 41,490 & 1.00002 & $\mathbf{0 . 9 1 4}$ \\
Overall cultural congruence & 699 & 6,369 & $6,019.5$ & 1.00017 & $\mathbf{0 . 9 8 7}$ \\
\hline
\end{tabular}

* - Ferguson's coefficient 
We then proceeded to calculate the discriminatory power of the test, i.e., its capacity to differentiate respondents between those with the highest and those with the lowest scores (see Table 3).

\section{Discussion}

The goal of our research was to identify typical age-specific rules that adolescents face on the day-to-day basis. Out of a long list, we were able to select those mentioned by the majority. It turned out there are 70 rules that regulate the behavior of adolescents in the Russian cultural context. Our next step was to check to what extent compliance with that invariable set of adolescence-specific rules may define cultural congruence. This will eventually determine the level of their socialization, behavior management capacity, and interaction with their surroundings.

Lev Vygotsky introduced the notion of a "social development situation" as a psychological marker for a certain age. It is an age-specific system of relationships between a child and his or her surroundings (Vygotsky, 1982). For example, matching the expectations of adults and obeying them is the dominant requirement for pre-school children. Dialogue is critically important for children up to the age of 10-12. Adults are the center of their social development situation. It is different for adolescents, though, who consider peers as an important factor. In their research, Jorien van Hoorn, Eric van Dijk, Rosa Meuwese, Carolien Rieffe, and Eveline A. Crone demonstrate that it is peer attitude that regulates adolescents' behavior. If the norms are asocial, but viewed positively by peers, adolescents will act in an asocial manner.

Our research also revealed the role of peers. Factor analysis allowed us to identify four major categories for the rules regulating adolescent behavior in the Russian cultural context. We will now detail each of the categories, or factors.

The first factor, Management, features rules on time and schedule management. These rules help to bring teenage behavior as closely as possible to the behavior patterns of an adult: "Eat healthy food," "Keep your room clean and tidy," "Wake up at the right time," etc. According to Lev Vygotsky, adolescents are usually keen to become adults. It is seen as a personal achievement for adolescents and they seek to identify themselves with adults. The ability to manage your time, and plan your schedule and activities, is an attribute of an adult; therefore teenagers want to behave like grownups. This makes Management a factor that is substantively valid for adolescence.

Safety rules grouped into the second factor are listed by pre-school children aged 5-6 (Bayanova \& Mustafin, 2016) and primary school students aged 7-11 (Bayanova et al., 2016). They are relevant for adolescents, too. However, at age 12 teenagers are learning to predict consequences, so they can pinpoint which rules they have to comply with because non-compliance might undermine their psychological safety. Teenagers know their psychological safety would be threatened if the rule is broken. For instance, Safety includes such rules as "You cannot leave without informing your parents," "Do not laugh at your teacher," and "Do not drink alcoholic beverages." Breaking the norms would entail consequences; therefore teenagers see them as rules. Younger children are not mature enough to compre- 
hend those rules. If the rule regarding relationships with a teacher (laughing at the teacher) is included in the Safety factor, it means that it is dangerous for a teenager to laugh at the teacher because of the degree of punishment which would result.

The third factor, Studies, includes rules that teenagers must follow at school, including while interacting with adults and teachers, doing their homework, or in class.

The fourth factor, Social Interaction, includes rules that determine teenage behavior toward their peers, e.g., the ability to stand up for one's self, keep one's promises, and be appreciative. Loyalty is generally considered to be a widespread value among Russian adolescents. The concept is encapsulated in the "Do not inform on your friends" rule. It refers to a situation in which adults are looking for a guilty party, and the adolescent knows for sure that his or her peer is guilty, but he or she will not give away the name. Adolescents will not betray their peers by informing on them. Other teenagers will approve of this attitude; therefore this kind of behavior acts as a rule regulating teenage conduct.

Analysis of all the rules grouped under each factor yields an image of an ideal social subject as perceived by adolescents. A good friend is one who can keep his or her promise, act in a noble way, and respect the opinion of other people. This image encompasses the rules that determine certain behavior patterns for adolescents in the Russian cultural context.

\section{Conclusion}

Our research pioneers in highlighting common rules out of a multitude that adolescents face in day-to-day life. These are permanent and sustainable adolescencespecific rules. All the rules that regulate the lives, school behavior, and interaction of Russian teenagers can be placed into four groups that are in line with existing science on teenage psychology: adolescents control their behavior while dealing with other people, and they also need to follow the rules for their own safety. Rules also play a vital role in shaping teenage behavior at school, as well as in their mapping out their day and taking care of themselves. Four factors were obtained by factor analysis. Each of the factors has a meaningful unity of rules. These factors are confirmed by psychometric assessments of their validity and reliability.

The cultural congruence test is a practical tool that can measure the level of conformity of adolescent behavior to age-specific rules. The rules that determine behavioral patterns to be adopted in adolescence are grouped into four factors: management, safety, studies, and social interaction. The test text can be found in the appendix to this article (see Appendix). Since this study focuses on the techniques involved in constructing the age-specific rules for adolescents, the potential for future work must still be clarified in further studies, on areas such as cultural congruence of a teenager and different psychological features of his character, temperament, manifestations of social qualities, etc.

\section{Acknowledgements}

The research was funded by the Russian Foundation for Basic Research (Project No. 17-29-02092 ofi_m). 


\section{References}

Bayanova, L.F., \& Mustafin, T. (2016). Factors of compliance of a child with rules in a Russian cultural context. European Early Childhood Education Research Journal, 24(3), 357-364. https://doi.org/1 0.1080/1350293X.2016.1164394

Bayanova, L.F., Tsivilskaya, E.A., Bayramyan, R.M., \& Chulyukin, K.S. (2016). A cultural congruence test for primary school students. Psychology in Russia: State of the Art, 9(4). https://doi. org/10.11621/pir.2016.0408

Bochaver, A.A., Korzun, A.N., \& Polivanova, K.N. (2017). Ulichnyy dosug detey i podrostkov [Outdoor Pastimes of Children and Teenagers]. Psychology. Journal of Higher School of Economics, 14(3), 485-505. https://doi.org/10.17323/1813-8918-2017-3-470-490

Desrichard, O., Roche, S., \& Begue, L. (2007). The theory of planned behavior as mediator of the effect of parental supervision: A study of intentions to violate driving rules in a representative sample of adolescents. Journal of Safety Research, 38(4), 447-452. https://doi.org/10.1016/j.jsr.2007.01.012

Dubrovina, I.V., \& Prikhozhan, A.M. (2003). Vozrastnaya i pedagogicheskaya psikhologiya [Developmental and educational psychology]. Akademiya. Seriya: Vysshee obrazovanie.

Feldstein, D.I. (2010). Izmenyayushchiysya rebenok v izmenyayushchemsya mire: psikhologo-pedagogicheskie problemy novoy shkoly [A changing child in a changing world: the psychological and pedagogical problems of the new school]. National Psychological Journal, 2, 6-11.

Grudinin, N.S. \& Gryaznova, D.V. (2015). Prestupnost' molodezhi v sovremennoy Rossii: prichiny, tendentsii, puti protivodeystviya [Youth criminality in modern Russia: reasons, tendencies, ways of combating]. Nauka-rastudent.ru, 04(16). Retrieved from http://nauka-rastudent.ru/16/2522/

Ghani, F.A., Kamal, S.A., \& Aziz, A.A. (2014). The Implication of Parenting Styles on the Akhlak of Muslim Teenagers in the South of Malaysia. Procedia - Social and Behavioral Sciences, 114, 761-765. https://doi.org/10.1016/j.sbspro.2013.12.781

Golberg-Looney, L.D., Sanchez-SanSegundo, M., Ferrer-Cascales, R., Smith, E.R., AlbaladejoBlazquez, N., \& Perrin, P.B. (2015). Adolescent drinking in Spain: Family relationship quality, rules, communication, and behaviors. Children and Youth Services Review, 58, 236-243. https:// doi.org/10.1016/j.childyouth.2015.09.022

Grachev, A.V., \& Bazhinova, A.A. (2016) Osobennosti suizidalnogo povedenia podrostkov [Features of suicidal behavior in adolescence]. Territory of Science, 4, 8-12

Lachal, J., Orri, M., Moro, M.R., \& Revah-Levy, A. (2015). Perspectives des adolescents et jeunesadultessur le suicide :uneméta-synthèse qualitative. Neuropsychiatrie de l'Enfance et de l'Adolescence, 63(7), 473-481. https://doi.org/10.1016/j.neurenf.2015.03.002

Lazareva, T.A. (2009). Vospitatel'nye pozitsii roditeley i ikh otsenka podrostkami [Parental pedagogical attitudes and their perception by adolescents]. Izvestiia Rossiiskogo Gosudarstvennogo Pedagogicheskogo Universiteta im. A. I. Gertsena [Izvestia: Herzen University Journal of Humanities \& Science], 94, 130-135. Retrieved from https://lib.herzen.spb.ru/text/IZV94_p1_8.pdf

Lavrichenko, O.V. (2013). Lichnostnye determinanty protestnogo povedeniya podrostkov [Personal determinants of protest behavior of adolescents]. Bulletin of the South Ural State University, Series Psychology, 6(3), 35-41. Retrieved from https://cyberleninka.ru/article/n/lichnostnye-determinanty-protestnogo-povedeniya-podrostkov

Lichko, A.E. (2010). Psikhopatii i aktsentuatsii kharaktera u podrostkov [Psychopathies and accentuations of the character of teenagers]. Moscow: Rech'

Mullins, D., \& Tisak, M.S. (2006). Moral, conventional, and personal rules: The perspective of foster youth. Journal of Applied Developmental Psychology, 27(4), 310-325. https://doi.org/10.1016/j. appdev.2006.04.003

Pedersen, S., Grønhøj, A., \& Thøgersen, J. (2015). Following family or friends. Social norms in adolescent healthy eating. Appetite, 86, 54-60. https://doi.org/10.1016/j.appet.2014.07.030 
Urmeneta, Ana R. (2014). Reification Processes of Social Norms in Children and Adolescents. Procedia - Social and Behavioral Sciences, 116, 1810-1818. https://doi.org/10.1016/j.sbspro.2014.01.476

Van Hoorn, J., van Dijk, E., Meuwese, R., Rieffe, C., \& Crone, E.A. (2016). Peer Influence on Prosocial Behavior in Adolescence. Journal of Research on Adolescence, 26(1), 90-100. https://doi. org/10.1111/jora.12173

Veraksa, N.E. (2000). Personality and Culture: Structural and Dialectic Approach. Peremeni, 1, 81107.

Veraksa, N.E., \& Veraksa, A.N. (2018). Lev Vygotsky's cultural-historical theory of development and the problem of mental tools. Psychologist Papers, 39(2), 150-154. https://doi.org/10.23923/pap. psicol2018.2862

Vygotsky, L.S. (1978). Mind in society: The development of higher psychological processes. Cambridge, MA: Harvard University Press.

Vygotsky, L.S. (1982). Sobranie sochinenii v 6 tomakh [Collection of works: in 6 volumes]. V.2. Moscow: Pedagogika.

Vygotsky, L.S. (1996). Izbrannye psikhologicheskie Trudy [Selected Psychological Studies]. Moscow: APN RSFSR.

Warner, T.D., Giordano, P.C., Manning, W.D., \& Longmore, M.A. (2011). Everybody's doin' it (right?): Neighborhood norms and sexual activity in adolescence. Social Science Research, 40(6), 16761690. https://doi.org/10.1016/j.ssresearch.2011.06.009

Zhang, Z., \& Arvey, R.D. (2009). Rule-breaking in adolescence and entrepreneurial status: An empirical investigation. Journal of Business Venturing, 24(5), 436-447. https://doi.org/10.1016/j.jbusvent.2008.04.009

Original manuscript received February 02, 2019 Revised manuscript accepted August 25, 2019

First published online September 30, 2019 


\section{Appendix}

Please rate the rules on the list on a five-point scale, where:

$1=\quad$ It is not an important rule, and I never follow it

$2=\quad$ I would rather break the rule because I do not believe it is binding

$3=\quad$ I may follow the rule but I may also choose to break it (50/50)

$4=\quad$ I take the rule as guidance

$5=\quad$ I always strictly follow the rule

\begin{tabular}{|c|c|}
\hline No. & Rule \\
\hline 1. & Get good marks \\
\hline 2. & Comply with dress code, dress neatly \\
\hline 3. & Do your homework \\
\hline 4. & Behave yourself \\
\hline 5. & Obey people older than you \\
\hline 6. & Do not use foul language \\
\hline 7. & Be polite \\
\hline 8. & Respect others \\
\hline 9. & Help everyone / each other \\
\hline 10. & Comply with etiquette rules \\
\hline 11. & Do not engage in brawls \\
\hline 12. & Do not argue with instructors \\
\hline 13. & Do not be late \\
\hline 14. & Follow your daily routine \\
\hline 15. & Keep your room clean and tidy \\
\hline 16. & Behave in a decent way \\
\hline 17. & Wake up at the right time in the morning \\
\hline 18. & Do not cheat other people \\
\hline 19. & Respect people older than you \\
\hline 20. & Do not speak during class \\
\hline 21. & Give up your seat to seniors \\
\hline 22. & Eat healthy food \\
\hline 23. & Do not smoke \\
\hline 24. & Respect the opinions of other people \\
\hline 25. & Go to bed at the right time \\
\hline 26. & Do not miss classes \\
\hline 27. & Do not insult each other \\
\hline
\end{tabular}


28. Do not drink alcoholic beverages

29. Follow school rules

30. Do not stay out too late

31. Have your meals at the right time

32. Wash the dishes

33. Do not play computer games

34. Do not spend too much time on social media

35. Be appreciative

36. Keep your promise

37. Make your bed

38. Be a good friend

39. Do not talk with strangers

40. Do not inform on your friends

41. Stand up for yourself

42. Do not play with matches/fire

43. Exercise in the morning

44. Do not take someone else's belongings without permission

45. Keep your posture

46. Do not laugh at your teacher

47. Do not harass the other gender

48. Do not use obscenities in your conversations with friends

49. Do not leave without informing your parents

50. Plan your day in advance

51. Take care of yourself

\section{Test Key:}

Factor 1 - Management: 14, 15, 17, 22, 25, 31, 32, 33, 34, 37, 43, 44, 45, 50.

Low: 14-40. Average: 41-59. High: 60-70.

Factor 2 - Safety: 6, 11, 23, 26, 27, 28, 29, 30, 39, 42, 46, 47, 48, 49.

Low: 14-49. Average: 50-67. High: 68-70.

Factor 3 - Studies: 1, 2, 3, 4, 5, 7, 9,10, 12, 13, 16, 18, 19, 20.

Low: 14-49. Average: 50-64. High: 65-70.

Factor 4 - Social Interaction: 8, 21, 24, 35, 36, 38, 40, 41, 51.

Low: 9-35. Average: 36-44. High: 45.

The overall level of cultural congruence is calculated as a sum of four factors. Low: 51-179. Average: 180-231. High: 232-255. 


\begin{tabular}{|c|c|c|c|c|c|}
\hline Standard ten & Management & Safety & Studies & $\begin{array}{c}\text { Social } \\
\text { Interaction }\end{array}$ & $\begin{array}{c}\text { The overall } \\
\text { level of cultural } \\
\text { congruence }\end{array}$ \\
\hline $\mathbf{1}$ & $14-34$ & $14-40$ & $14-44$ & $9-31$ & $51-161$ \\
\hline $\mathbf{2}$ & $35-40$ & $41-47$ & $45-49$ & $32-35$ & $162-181$ \\
\hline $\mathbf{3}$ & $41-45$ & $48-55$ & $50-55$ & $36-38$ & $182-197$ \\
\hline $\mathbf{4}$ & $46-48$ & $56-58$ & 56 & $39-40$ & $198-202$ \\
\hline $\mathbf{5}$ & $49-53$ & $59-62$ & $57-59$ & $41-42$ & $203-212$ \\
\hline $\mathbf{6}$ & $54-57$ & $63-66$ & $60-63$ & 43 & $213-224$ \\
\hline $\mathbf{7}$ & $58-62$ & $67-68$ & $64-66$ & 44 & $225-236$ \\
\hline $\mathbf{8}$ & $63-67$ & 69 & $67-68$ & 44 & $237-246$ \\
\hline $\mathbf{9}$ & $68-69$ & 69 & 69 & 44 & $247-250$ \\
\hline $\mathbf{1 0}$ & 70 & 70 & 70 & 45 & $251-255$ \\
\hline
\end{tabular}

To cite this article: Bayanova, L.F., Minyaev, O.G. (2019). Cultural Congruence Test for Russian Adolescents. Psychology in Russia: State of the Art, 12(3), 163-176. DOI: 10.11621/ pir.2019.0304 